\title{
Effects of Musculoskeletal Disease Prevention and Treatment Customized Exercise Program according to Various Music Tempo on the Pain, Posture, and Function of Auto Parts Manufacturing Workers
}

\author{
Ho Kima, Wonseob Shin ${ }^{a, b}$

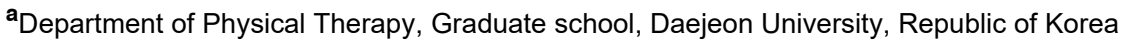 \\ ${ }^{b}$ Department of Physical Therapy, College of Health and Medical Science, Daejeon University, Republic of Korea
}

\begin{abstract}
Objective: The purpose of this study is to investigate the effect of exercise programs according to various music tempo on pain, posture, and function of automobile parts manufacturing workers.
\end{abstract}

Design: Two-group pretest-posttest design.

Methods: This study was an exercise program tailored to the prevention and treatment of musculoskeletal diseases were performed for a total of 4 weeks and 3 times a week for 60 minutes. The exercise program consisted of customized exercises according to the characteristics of the subject's musculoskeletal system. The subject provided music during the exercise program, and the group who applied the fast tempo music listened to the music of 120 140 bpm, and the group who applied the slow tempo music listened to the music of the low tempo of $60 \sim 80 \mathrm{bpm}$.

Results: Significant differences were found in pain and physical function before and after the fast tempo music group and the slow tempo music group $(\mathrm{p}<0.01)$. However, there was a significant difference in posture characteristics only in the fast tempo music group $(\mathrm{p}<0.01)$. In terms of pain, physical function, and posture characteristics, the fast tempo music group showed significant improvement compared to the slow music tempo group $(\mathrm{p}<0.05)$.

Conclusions: A customized exercise program using fast-tempo music and slow-tempo music to workers in the automobile parts manufacturing industry, significant differences in pain, physical function, and posture characteristics applied with fast-tempo music were found. In the future, applying an exercise program with a fast tempo is expected to help improve musculoskeletal disorders.

Key Words: Music, Worker, Musculoskeletal disorder, Selective Functional Movement Assessment, Pain

\section{서론}

산업이 자동화되고 분업화를 통해 근로자의 업무가 단 순화와 분업화가 동시에 이뤄져 왔다. 이에 근로자는 단순 하면서도 반복적인 움직임과 자세를 취하게 된다. 2016년 안전보건공단의 산업재해분석에 따르면, 근골격계 질환자 가 35세 이상에서 급증하고 있으며, 신체부담작업으로 인 한 근골격계 질환 발생율이 $29.7 \%$, 제조업의 근로자의 산
업재해는 $40 \%$ 에 이른다고 하였다[1].

사업체 내의 작업관련성 근골격계 질환(work-related musculoskeletal disorder, WMSDs)은 작업과 관련하여 신체 특정 부위 및 근육 뼈대계의 과도한 활동으로 인해 신 체에 미세한 손상이 누적되어 발생하는 만성 건강 장해로 정의하며[2], 산업보건기준에 관한 규칙 제 142 조에 의거 해 부적절한 작업자세, 소음, 온도 등의 요소들에 의하여 발생하고 체간, 상-하지의 근육-신경계와 다른 조직들에게

Received: Feb 2, 2021 Revised: Feb 17, 2021 Accepted: Feb 17, 2021

Corresponding author: Wonseob Shin (ORCID https://orcid.org/0000-0002-6515-7020)

Department of Physical Therapy, College of Health and Medical Science, Daejeon University, Applied Science Building, 62, Daehak-ro, Dong-gu, Daejeon, 34520, Republic of Korea

Tel: 82-42-280-2294 Fax: 82-42-280-2295 E-mail: shinws@dju.kr

This is an Open-Access article distributed under the terms of the Creative Commons Attribution Non-Commercial License (http://creativecommons.org/licenses/ by-nc/4.0) which permits unrestricted non-commercial use, distribution, and reproduction in any medium, provided the original work is properly cited.

Copyright @ 2021 Korean Academy of Physical Therapy Rehabilitation Science 
나타나는 것 또한 근골격계 질환으로 정의한다[3]. 이러한 문제들은 산재보상 비용의 증가로 인한 경제적 문제, 노동 력 손실로 인한 사회적 문제등을 일으켜 사업장에서는 근 로자의 근골격계 문제들을 예방하고 해결하기 위해 작업 환경개선 뿐만 아니라 유해인자조사, 근골격계 질환 예방 프로그램들을 적용해 문제들을 개선시키고 있다[4]. 근골 격계 질환 예방 프로그램은 통증, 재해율, 병가와 재정적인 방향에서 긍정적인 개선을 미친다고 하였고 근로자와 사 업주 모두에게 긍정적인 방향성을 제공한다고 보고하고 있어 근로자의 근골격계 질환 개선 방안으로 운동에 대한 필요성을 언급하고 있다[5]. 또한 자신의 신체 특성에 맞지 않는 근로자의 작업 환경과 적절하지 않는 자세로 장시간 반복적인 작업과 유지로 각종 근골격계 질환으로 자유롭 지 못한 상황에서의 사전 예방과 개선 방안으로 운동을 통 한 개선 방향성을 언급하고 있다[6,7].

최근에는 운동을 시행하는데 있어 음악을 추가적으로 적용하여 신체적인 개선 및 통증과 같은 유해 요인과 심리 적인 개선에 영향을 미친다는 연구들이 진행되고 있다. 선 행 연구에서는 음악을 적용함과 동시에 운동을 수행하면 신체적인 성능과 생리적 효과, 심리적인 방면에서 도움을 준다고 보고하고 있다. 카테콜라민(catecholamine), 코티 졸(cortisol)과 같은 스트레스 호르몬, 자율신경계 및 통증 조절 능력 개선에도 도움을 준다고 보고하고 있다[8]. 유산 소 운동을 수행 시 빠르고 강한 템포의 음악을 적용하면 신 체적 성능면에서 긍정적인 영향을 미친다고 보고하였으며 [9], 느린 템포 음악을 운동과 함께 적용 시, 심박수와 혈압 및 호흡률 회복 개선에 긍정적인 영향을 미칠 뿐만 아니라 운동 후 회복에도 영향을 미친다고 보고하고 있다[10]. 8 주간 음악을 병행한 몸통 안정화 운동을 적용하였을 때, 통 증과 척추 정렬, 복부 및 허리 근육의 기능 개선에 긍정적 인 영향을 미친다고 하였다[11]. 이렇게 음악을 다양하게 적용시켜 많은 효과를 입증한 방면에 아직까지 근골격계 손상 위험도가 높은 공장 근로자들을 대상으로 한 맞춤형 운동 프로그램과 음악을 융합하여 효과 입증을 연구한 논 문은 미비한 실정이다.

이에 본 연구의 목적은 근골격계 질환 예방 및 치료 맞 춤형 운동 프로그램에 빠른 템포 음악과 느린 템포 음악을 추가하여 자동차 부품 제조업 근로자들에게 적용해 대상 자들의 근골격계 통증, 신체적 기능, 자세 특성을 비교하여 어떠한 영향을 미치는지 알아보고자 한다.

\section{연구 방법}

\section{연구 대상}

본 연구의 대상자는 충청남도 서산시 소재의 $\mathrm{H}$ 자동차 부품 공장에서 2019년에 근무하여 한달동안 운동프로그
램에 참여하는 자를 대상으로 하였다.

대상자의 선정 조건은 다음과 같다. 첫째, 연령이 3 세 이상 6 세 미만인 자. 둘째, 음악을 감상하는데 청력 손실이 없는 자이다. 대상자의 제외 조건은 다음과 같다. 첫째, 최 근 3 개월간 정형외과, 신경학적인 손상으로 인한 수술을 받은 자. 둘째, 실험 기간 중 진통제를 복용한 자, 셋째, 통 증으로 인해 운동 프로그램을 온전히 수행하지 못하는 자, 넷째, 연구 일정의 출석률이 $80 \%$ 미만인 자이다.

대상자 산출은 Cohen의 표본추출 공식에 따른 표본 수 계산 프로그램인 G*Power 3.1.9.2 프로그램을 이용하여 산출하였다. 선행연구에서 분석하고자 하는 운동 치료의 그룹 간 효과에 대한 검정력을 유지하기 위해 효과크기 0.94 , 유의 수준 0.05 , 검정력 0.8 로 설정한 후 표본 크기를 산출한 결과 각 군의 최소 표본 크기는 15 명으로 전체 대 상자 수는 30 명을 필요로 했다. 본 연구는 많이 탈락자를 우려하여 총 46 명을 모집하였으며, 제외 조건과 중간 탈락 자를 제외하고 빠른 템포 음악 그룹 15명, 느린 템포 음악 그룹 16 명이 배정되어 총 31 명의 대상자가 연구에 참여하 였다[10]. 모든 대상자는 연구에 참여하는데 있어서 헬싱 키 선언에 제시된 안내와 설명을 듣고 서명을 통해 자발적 으로 실험에 참여하였다.

\section{연구 절차}

본 연구는 대상자 간의 근골격계 통증, 자세 특성, 신체 적 기능을 비교한 두 군 사전-사후검사 설계이다. 근골격계 질환 예방 및 치료 맞춤형 운동 프로그램은 총 4 주간 주 3 회 60 분 동안 수행되었으며, 운동 프로그램에는 준비운동 10 분, 맞춤형 유산소 운동 10 분, 맞춤형 코어 운동 15 분, 맞 춤형 근력 강화운동 15 분, 정리 운동 10 분으로 대상자의 근 골격계 특성에 따라 통증 조절, 자세와 신체 기능의 개선을 위한 맞춤형 운동들로 구성되었다. 대상자가 운동 프로그 램을 실시하는 도중 음악을 제공하였으며, 모든 평가는 운 동 프로그램 사전, 사후에 진행되었다[12](Figure 1).

\section{중재 방법}

\section{Musculoskeletal disease prevention and treatment customized exercise program}

모든 그룹 모두 치료사의 감독 및 보조 하에 근골격계 질환 예방 및 치료 맞춤형 운동 프로그램이 진행하였다. 부 상 예방을 위한 준비 운동으로 치료실내에서 걷기를 통한 몸 풀기와 어깨관절과 척추관절, 엉덩관절과 같은 가동성 이 높은 관절을 위주로 하는 동적 스트레칭을 각 5 분씩 적 용하였다. 서킷 트레이닝으로는 대상자들이 가진 근골격 계의 강화 지점을 대상으로 운동을 배정하였으며, 유산소 운동(줄넘기, PT체조 등) 10 분, 코어 운동(데드 버그, 버드 독, 프론트 플랭크, 사이드 플랭크, 크롤링 홀드, 허리 안정 


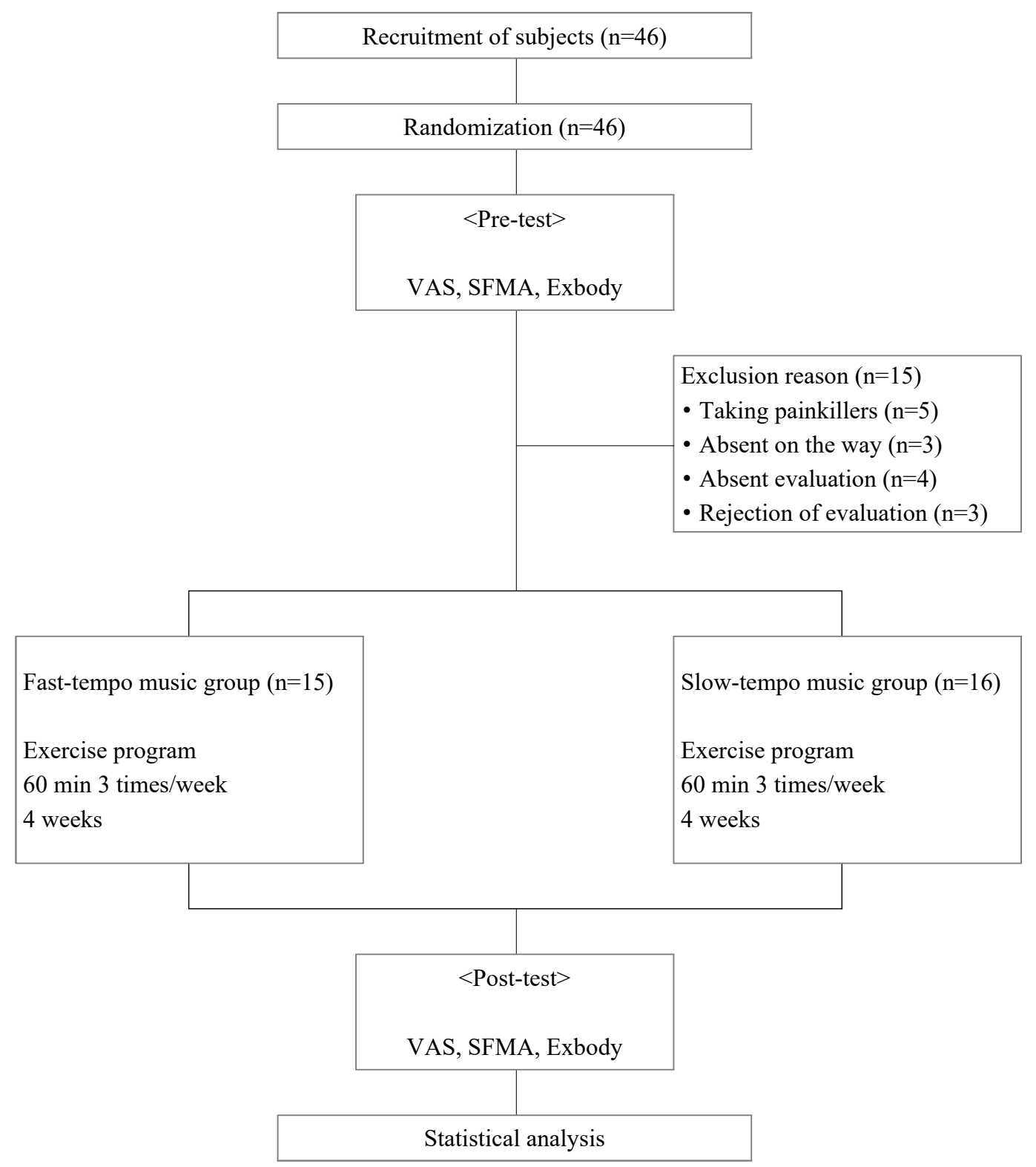

Figure 1. Procedure

화 운동 등) 15 분, 강화 운동(풀리 머신을 이용한 어깨관절 강화 운동, 세라밴드를 이용한 저항 운동, 스쿼트 등) 15 분을 적용하였다. 쿨 다운은 대상자들이 피로감을 호소하는 부위 와 운동을 진행한 부위에 정적 스트레칭과 폼롤러를 이용한 자가 근막 이완 기법을 각 5 분씩 적용하였다(Table 1).

\section{Music application}

대상자들이 운동을 진행할 때 각 군마다 다른 템포의 음 악을 제공하였다. 빠른 템포 음악을 적용한 군은 120 140 $\mathrm{bpm}$ 의 경쾌하고 빠른 리듬의 음악들을 듣게 하였고[13], 느린 템포 음악을 적용한 군은 심리적으로 안정감을 느끼 게 하는 $60 \sim 80 \mathrm{bpm}$ 의 낮은 템포의 음악을 듣게 하였다
[14]. 모든 음악의 유형은 클래식 음악으로 일관하였다.

\section{측정 도구}

Pain

대상자의 통증 양상을 알아보기 위해 평가방법으로 visual analogue scale (VAS)를 이용하였다. VAS는 통증 강도를 측정하는 주관적인 평가도구로 0 부터 10 까지 통증 의 정도를 나타낸다. 0 은 통증에 대한 증상이 나타나지 않 는 상태, 10 은 참기 힘들 정도로 매우 극심한 통증이 있는 상태를 의미한다. 이 평가도구는 Intraclass Correlation Coefficients (ICC) 0.9로 높은 신뢰도를 가지고 있다[15]. 
Table 1. Musculoskeletal disease prevention exercise Program

\begin{tabular}{llll}
\hline Category & Exercise program & Method & Time \\
\hline Warming-up & Walking & Walk around the treatment room & $5 \mathrm{~min}$ \\
& Dynamic stretching & Applied mainly to the shoulder and hip joint & $5 \mathrm{~min}$ \\
Circuit training & Aerobic exercise & Using PT gymnastics or jump rope or another program & $10 \mathrm{~min}$ \\
& Core muscle training & Performs front and back muscle core exercise & $15 \mathrm{~min}$ \\
& Muscle strengthening & Using theraband or pully machine & $15 \mathrm{~min}$ \\
Cool-down & Static stretching & Simply apply static stretching & $5 \mathrm{~min}$ \\
& Myofascial release & Using foam roller & $5 \mathrm{~min}$ \\
\hline
\end{tabular}

\section{Physical function}

대상자의 신체적 기능 능력을 평가하기위해 selective functional movement assessment (SFMA) 척도를 사용하 였다. SFMA는 목벼 움직임, 상지 움직임 패턴, 다분절 굽 힘, 폄, 돌림에 대한 움직임, 한 다리 균형 유지, 오버 헤드 딥 스쿼트로 구성된 7개의 상위 계층 움직임으로 구성되며 모든 움직임 패턴이 적용 가능한 경우 양쪽 방향 모두 평가 하였다. 대상자에게 7가지 움직임 패턴에 대한 평가를 적 용하면 움직임이 기능적인지 기능 장애의 요소가 있는지 를 나타내는 정보를 제공하며, 점수가 낮을수록 신체 기능 이 높다. SFMA의 내적 신뢰도는 0.72-0.83으로 거의 완 벽한 일관성을 보이고 세 명의 평가자의 카파 계수에서 $83-88 \%$ 의 일관성을 나타낸다[16,17].

\section{Posture}

대상자의 신체 구조적인 부분을 알아보기 위해 Exbody (770 series; Exbody, Republic of Korea)를 사용하여 자 세 신체 지수를 평가하였다. 전방 자세, 측면 자세에서 남 성은 상의 탈의와 짧은 반바지를 착용하였고 여성은 신축 성 소재를 가진 티셔츠와 짧은 반바지를 착용하였다. 신체 장비에서 $2 \mathrm{~m}$ 떨어진 위치에서 평가를 실시하였다. 전방 자세는 양쪽 귓 볼, 어깨뼈 봉우리, 앞-위엉덩뼈가시, 무릎 뼈 중앙 부분, 정강뼈거친면, 발목 관절 중앙 부분에 마커 를 부착하였다. 측면 자세에서는 오른손을 가슴 위에 위치 시키고 턱관절 아래, 어깨뼈 봉우리, 엉덩뼈 능선 가장 윗 부분, 넙다리뼈 큰 돌기, 종아리뼈 머리, 복사뼈에 마커를 부착하였다. 두가지 자세에서의 점수의 합으로 신체 지수

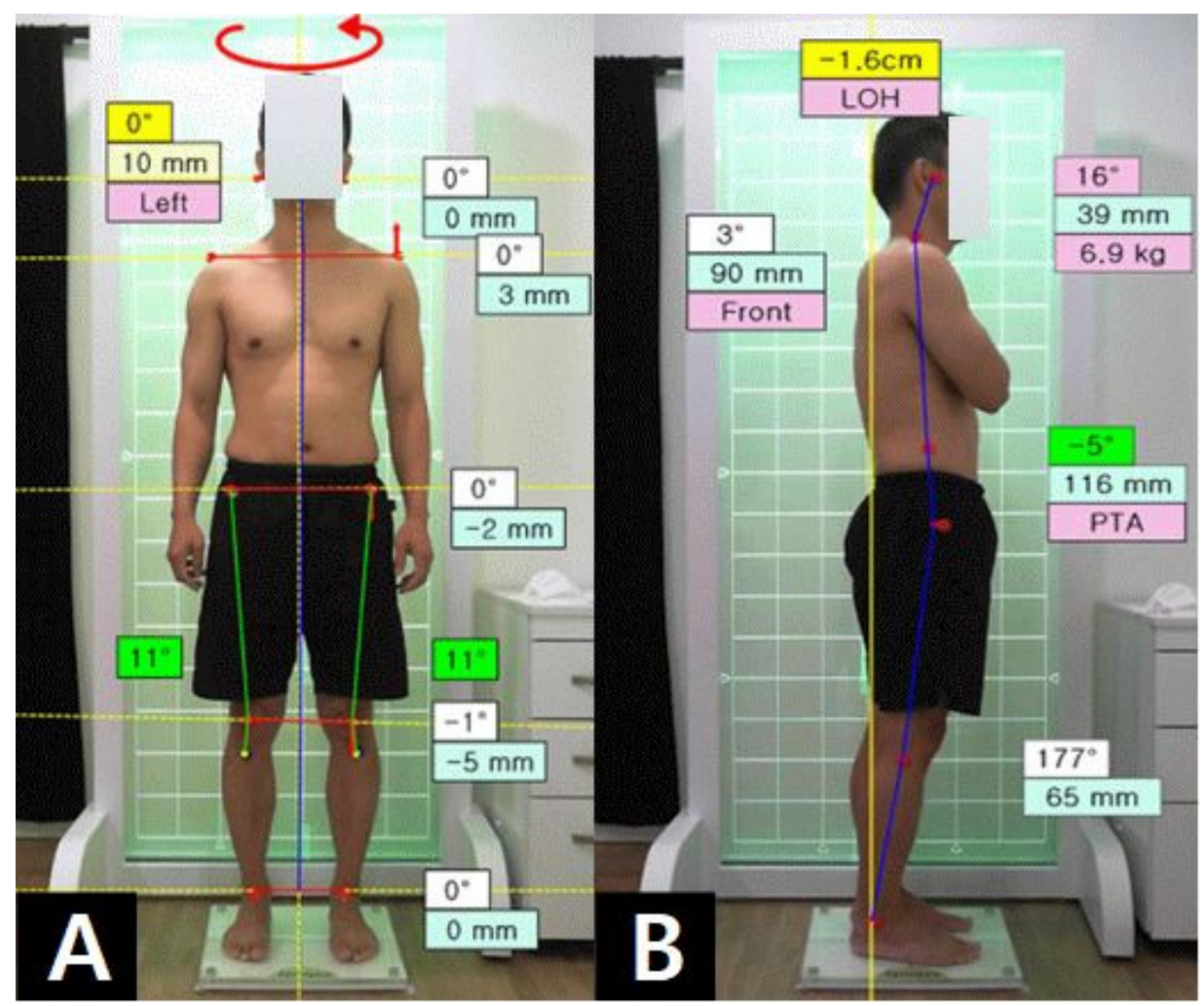

Figure 2. Exbody (A:Front posture view, B: Lateral view) 
가 분석되는데 신체 정렬 선은 전방 자세의 귓 볼, 어깨 기 울기, 골반 기울기, Q-각, 무릎 높이, 발목 높이 간의 차이 와 측면자세의 전방 머리 자세, 골반 회전 정도, 무릎 굽힘 또는 과다폄의 점수를 합하여 분석된다. 총 신체 지수의 수 치가 낮을수록 좋은 자세임을 나타낸다[18](Figure 2).

\section{자료 분석}

본 연구를 통해 수집된 자료는 IBM SPSS (SPSS ver. 25.0; IBM Co., USA)를 사용하여 통계분석을 실시하였 다. 대상자의 일반적 특성은 기술통계를 이용하여 평균과 표준편차를 제시하였으며, Shapiro-Wilk test를 통한 정규 성 검정을 실시하였다. 각 그룹 내의 전-후 효과를 비교하 고자 paired t-test를 실시하였고, 각 그룹 간 비교를 위해 변화량을 이용한 independent t-test를 실시하였다. 통계학 적 유의수준은 $\alpha=0.05$ 로 설정하였다.

\section{연구 결과}

본 연구에 참여한 빠른 템포 음악 군의 15 명과 느린 템 포 음악 군의 16 명의 일반적 특성은 제시된 표와 같으며, 성별, 나이, 키, 몸무게, 경력사항 등 모두 동질성을 확인할 수 있었다(Table 2).

통증의 변화에 대한 그룹 내 전-후 비교에서는 빠른 템 포 음악 군과 느린 템포 음악 군 모두 유의한 차이가 나타 나 통증의 감소를 확인할 수 있었으며 $(\mathrm{p}<0.01)$, 그룹 간 전 -후의 변화량의 비교에서는 빠른 템포 음악 군이 느린 템포 음악 군에 비해 통증에서 유의한 감소를 확인할 수 있었다 $(\mathrm{p}<0.01)$. 신체적 기능의 변화에 대한 그룹 내 전-후 비교 에서는 바른 템포 음악 군과 느린 템포 음악 군 모두 유의 한 차이가 나타나 신체적 기능 증진을 확인할 수 있었으며 $(\mathrm{p}<0.01)$, 그룹 간 전-후의 변화량의 비교에서는 빠른 템포 음악 군이 느린 템포 음악 군에 비해 신체적 기능에서 유의 한 차이를 확인할 수 있었다 $(\mathrm{p}<0.01)$. 자세 특성의 변화에 대한 그룹 내 전-후 비교에서는 빠른 템포 음악 군에서는 자세 개선에 대해 유의한 차이를 보였으나( $\mathrm{p}<0.01)$, 느린 템포 음악 군에서는 유의한 차이가 나타나지 않았다. 그룹
간 전-후의 변화량의 비교에서는 빠른 템포 음악 군이 느 린 템포 음악 군에 비해 자세 특성에서 유의한 차이를 확인 할 수 있었다 $(\mathrm{p}<0.01)($ Table 3$)$.

\section{고찰}

본 연구는 근골격계 질환 예방 및 치료 맞춤형 운동 프 로그램에 빠른 템포 음악과 느린 템포 음악을 융합하여 자 동차 부품 제조업 근로자들에게 적용해 대상자들의 근골 격계 통증, 신체적 기능, 자세 특성을 비교하여 어떠한 영 향을 미치는지 알아보고자 연구를 진행하였다. 본 연구의 결과, 통증과 신체적 기능, 자세 특성에서 빠른 템포 음악 군이 느린 템포 음악을 적용한 군보다 유의한 개선을 확인 할 수 있었다.

선행 연구에서는 근로자들을 대상으로 유산소 운동 프 로그램을 통해 근골격계 통증, 작업 능력, 신체 활동, 병가 에 대한 연구에서 유산소 능력은 향상되었지만 근골격계 통증 및 업무 향상도와 기타 요인을 개선시키는데 한계가 있었다[19]. 이에 다른 연구에서는 근로자가 종사하는 업 무에 따른 특성과 업무 환경에 기반한 프로그램을 제공하 는 것이 중요하다고 보고하고 있다[20]. 본 연구에서는 템 포에 상관없이 전, 후 비교에서 통증과 신체적 기능면에서 통계적으로 유의한 개선을 확인할 수 있었다. 이는 본 연구 에서 시행된 운동 프로그램이 근로자들의 업무 특성과 개 개인의 질환 특성에 따라 맞춤형으로 제공되었기에 운동 프로그램을 실시한 근로자들에게 긍정적인 영향을 미쳤을 것으로 사료된다.

운동과 같은 신체적 활동 환경에 음악을 함께 적용시키 면 대상자의 참여에 즐거움을 높여 동기 부여를 주며, 순응 도를 높여 건강상의 이점을 증진시킨다고 하였다[21]. 또 한 음악과 함께 운동을 할 시, 더 큰 신경근육계 및 운동 효 율을 촉진시켜 활동 대사 비용을 낮출 수 있다고 하였다 [22]. 그 중, 빠른 템포의 음악을 청취할 시, 전반적인 운동 내성과 신경근 피로 역치가 증가함을 제시하였다[23]. 고 강도 사이클 운동에 각각 다른 템포의 음악을 적용한 결과, 빠른 템포의 음악이 느린 템포의 음악에 비해 운동 수행력

Table 2. The General Characteristics of subjects $(n=31)$

\begin{tabular}{llll}
\hline & FTMG $(\mathbf{n}=\mathbf{1 5})$ & STMG $(\mathbf{n}=\mathbf{1 6})$ & $\mathbf{t}$ \\
\hline Sex $(\mathrm{M} / \mathrm{F})$ & $12 / 3$ & $14 / 2$ & 0.322 \\
Age $($ years $)$ & $38.33(6.74)$ & $41.62(6.46)$ & 1.387 \\
Height $(\mathrm{cm})$ & $172.80(7.01)$ & $173.50(7.65)$ & 0.265 \\
Weight $(\mathrm{kg})$ & $76.19(12.34)$ & $75.11(8.77)$ & -0.281 \\
Career (years) & $10.53(6.97)$ & $12.17(5.81)$ & 0.716 \\
\hline
\end{tabular}

Values are expressed as Mean (SD)

FTMG: fast-tempo music group, STMG: slow-tempo music group ${ }^{*} \mathrm{p}<0.05,{ }^{* *} \mathrm{p}<0.001$ 
Table 3. Comparison of pain, function, posture within the group and between group $(n=31)$

\begin{tabular}{|c|c|c|c|}
\hline Variables & FTMG $(n=15)$ & STMG $(n=16)$ & $\mathbf{t}$ \\
\hline \multicolumn{4}{|l|}{ VAS $(\mathrm{cm})$} \\
\hline Pre & $5.66(2.25)$ & $6.37(1.82)$ & 0.965 \\
\hline Post & $1.53(1.45)$ & $5.00(2.00)$ & $5.484^{* *}$ \\
\hline $\mathrm{t}$ & $8.328^{* *}$ & $3.780^{* *}$ & \\
\hline Change & $4.13(1.92)$ & $1.37(1.45)$ & $-4.523^{* *}$ \\
\hline \multicolumn{4}{|c|}{ SFMA (Points) } \\
\hline Pre & $26.06(6.22)$ & $22.06(7.16)$ & -1.655 \\
\hline Post & $6.40(4.57)$ & $14.87(6.04)$ & $4.378^{* *}$ \\
\hline $\mathrm{t}(\mathrm{p})$ & $12.072^{* *}$ & $4.862^{* *}$ & \\
\hline Change & $19.66(6.30)$ & $7.18(5.91)$ & $-5.685^{* *}$ \\
\hline \multicolumn{4}{|c|}{ Exbody (Index) } \\
\hline Pre & $42.93(12.29)$ & $39.87(12.03)$ & -0.700 \\
\hline Post & $31.13(8.55)$ & $37.18(11.32)$ & 1.671 \\
\hline$t(p)$ & $4.277^{* *}$ & 1.768 & \\
\hline Change & $11.80(10.68)$ & $2.68(7.03)$ & $2.823^{*}$ \\
\hline
\end{tabular}

Values are expressed as Mean (SD).

FTMG: fast-tempo music group, STMG: slow-tempo music group ${ }^{*} \mathrm{p}<0.05,{ }^{* *} \mathrm{p}<0.01$

뿐만 아니라 생리적 효과에서 더 긍정적인 개선을 보였다 고 보고하였다[24]. 반면에 느린-중간 템포의 음악은 고강 도 활동 중 진정 효과를 불러 일으켜 정서적인 방면에 긍정 적인 영향을 미친다고 하였으나, 운동 강도에 따라 최적의 음악 템포를 적용하는 것이 중요하다고 언급하였다[25]. 또한, 선행 연구에서의 대상자들은 운동 중, 느린 템포의 음악보다 중간 및 빠른 템포의 음악의 선호함을 언급하였 다[26]. 본 연구에서는 빠른 템포 음악 군이 느린 템포 음 악 군에 비해 통증, 신체적 기능, 자세 특성 모두 유의한 차 이를 보여 긍정적인 방향성을 제시하였다. 이에 본 연구에 서 실시한 맞춤형 운동 프로그램과 같이 적용한 느린 템포 의 음악보다 빠른 템포의 음악을 적용하는 것이 운동의 강 도뿐만 아니라 동기부여와 운동 수행력에 영향을 미쳤을 것이라 사료된다. 또한, 느린 템포의 음악을 적용한 군에서 는 자세 특성에는 전, 후 비교에서 유의한 차이가 나타나지 않았는데, 이는 빠른 템포의 음악을 적용한 군의 운동 수행 의 동기부여를 더욱 촉진시켜 운동 수행력을 증진시켰을 것으로 사료된다. 이에 빠른 템포의 음악을 적용한 운동프 로그램은 향후 근로자뿐만 아니라 임상의 근골격계 질환 자에게도 새롭게 적용되어 객관적인 자료를 제공할 것으 로 기대한다. 본 연구결과를 바탕으로 다양한 유형 및 템포 의 음악과 물리치료를 융합한 다양한 치료 프로토콜이 새 롭게 연구되고 임상에 적용되길 바란다.

본 연구의 제한점으로 첫째, 실험 시간을 제외하고는 다 른 음악의 청취에 통제를 하지 못하였다. 둘째, 실험 시간
을 제외하고 개인의 신체적 활동을 통제하는데 어려움이 있다. 셋째, 실험의 일관성을 위해 대상자가 선호하는 음악 에 맞추지 못하였다. 향후 이러한 제한점을 보완하면 더욱 발전된 연구가 될 것으로 기대한다.

\section{참고 문헌}

1. Kim WH. Effect of an Active Tailored Exercise Program on Pain and Oswestry Disability Index in Automobile Manufacturing Workers with Musculoskeletal Symptoms of the Low Back. J Korean Soc Phys Med. 2019;14:109-16.

2. Kim YC, Bae CH. Study of the relation between work-related musculoskeletal disorders and job stress in heavy industry. J Korean soc saf. 2006;21: 108-13.

3. Jeong BY. Ergonomics' role for preventing musculoskeletal disorders. J Ergon Soc Kor. 2010;29:393404.

4. Jung KH, Lee SK, Kwon O, You HC, Kim DS. Structural Analysis and Practitioner Needs Survey for a WMSD Prevention Program. J Ergon Soc Korea. 2005;24:35-41.

5. Lee KW, Kim WH. Effect of physical therapy based 
tailored exercise program on pain, accident incidence rates, and lost days of work in manufacturing worker: single subject design. J Korean Soc Phys Med. 2017;12:113-20.

6. Kwon IH, Shin WS. Characteristics of muscle strength and posture among automobile parts manufacturing workers and the necessity of the musculoskeletal injury prevention program. J Korean Soc Phys Med. 2019;14:173-81.

7. Kim HJ, Shin WS. Three-dimensional Analysis of the Spine using Formetric 4D according to Upper Limb Movement and Resistance Application. J Korean Soc Phys Med. 2020;15:69-77.

8. Yamasaki A, Booker A, Kapur V, Tilt A, Niess H, Lillemoe $\mathrm{KD}$, et al. The impact of music on metabolism. Nutrition. 2012;28:1075-80.

9. Edworthy J, Waring H. The effects of music tempo and loudness level on treadmill exercise. Ergonomics. 2006;49:1597-610.

10. Rane PR, Gadkari JV. The effect of slow and fast musical tempo on post-exercise recovery on recovery period in young adults. Natl J Physiol Pharm Pharmacol. 2017;7:22.

11. Lee D, Lee Y. Effects of the trunk stabilization exercise combine in the musical tempo on lumbar lordosis angle, muscle activity and pain. J. Korean soc. integr. med. 2018;6:83-9.

12. Rasotto C, Bergamin M, Sieverdes JC, Gobbo S, Alberton CL, Neunhaeuserer D, et al. A tailored workplace exercise program for women at risk for neck and upper limb musculoskeletal disorders. J Occup Environ Med. 2015;57:178-84.

13. Ko MG, Oh BS. The Relationships between Music, Cortisol, Calcium, Hemodynamics and Jogging Exercise in Male Collage Students. Journal of Sport and Leisure Studies 2013;51:699-711.

14. Styns F, van Noorden L, Moelants D, Leman M. Walking on music. Hum Mov Sci. 2007;26:769-85.

15. Bijur PE, Silver W, Gallagher EJ. Reliability of the visual analog scale for measurement of acute pain. Acad Emerg Med. 2001;8:1153-7.

16. Glaws KR, Juneau CM, Becker LC, Di Stasi SL, Hewett TE. Intra- and inter-rater reliability of the se- lective functional movement assessment (sfma). Int J Sports Phys Ther. 2014;9:195-207.

17. Kim JE, Kim C, Kim S. Effects of corrective exercises on selective functional movement assessment and health risk appraisal in middle-aged women. Phys Ther Rehabil Sci. 2016;5:185-92.

18. Kim SD, Hong SH, Kim JH. The effects of neck-scapula corrective exercise on static posture balance and muscle stiffness. Journal of Sport and Leisure Studies 2017;68:601-10.

19. Gram B, Holtermann A, Bültmann U, Sjøgaard G, Søgaard K. Does an exercise intervention improving aerobic capacity among construction workers also improve musculoskeletal pain, work ability, productivity, perceived physical exertion, and sick leave?: a randomized controlled trial. J Occup Environ Med. 2012;54:1520-6.

20. Sihawong R, Janwantanakul P, Jiamjarasrangsi W. A prospective, cluster-randomized controlled trial of exercise program to prevent low back pain in office workers. Eur Spine J. 2014;23:786-93.

21. Stork MJ, Karageorghis CI, Ginis KAM. Let's Go: Psychological, psychophysical, and physiological effects of music during sprint interval exercise. Psychol Sport Exerc. 2019;45:101547.

22. Bacon CJ, Myers TR, Karageorghis CI. Effect of music-movement synchrony on exercise oxygen consumption. J Sports Med Phys Fitness. 2012;52:359.

23. Centala J, Pogorel C, Pummill SW, Malek MH. Listening to Fast-Tempo Music Delays the Onset of Neuromuscular Fatigue. J Strength Cond Res. 2020; 34:617-22.

24. Waterhouse J, Hudson P, Edwards B. Effects of music tempo upon submaximal cycling performance. Scand J Med Sci Sports. 2010;20:662-9.

25. Karageorghis CI, Jones L. On the stability and relevance of the exercise heart rate-music-tempo preference relationship. Psychol Sport Exerc. 2014;15: 299-310.

26. Karageorghis CI, Jones L, Priest DL. Revisiting the relationship between exercise heart rate and music tempo preference. Res Q Exerc Sport 2011;82:274-84. 